\title{
Band-Gap Engineering of $\mathrm{NaNbO}_{3}$ for Photocatalytic $\mathrm{H}_{2}$ Evolution with Visible Light
}

\author{
Peng Li, ${ }^{1}$ Hideki Abe, ${ }^{1,2,3}$ and Jinhua Ye $e^{1,2,4}$ \\ ${ }^{1}$ Catalytic Materials Group, Environmental Remediation Materials Unit, National Institute for Materials Science (NIMS), \\ 1-1 Namiki, Tsukuba, Ibaraki 305-0044, Japan \\ ${ }^{2}$ TU-NIMS Joint Research Center, School of Materials Science and Engineering, Tianjin University, 92 Weijin Road, \\ Nankai District, Tianjin 300072, China \\ ${ }^{3}$ PRESTO, Japan Science and Technology Agency (JST), 4-1-8 Honcho Kawaguchi, Saitama 332-0012, Japan \\ ${ }^{4}$ International Center for Materials Nanoarchitectonics (WPI-MANA), National Institute for Materials Science (NIMS), \\ 1-1 Namiki, Tsukuba, Ibaraki 305-0044, Japan
}

Correspondence should be addressed to Hideki Abe; abe.hideki@nims.go.jp

Received 4 July 2014; Accepted 3 August 2014; Published 26 August 2014

Academic Editor: Wenjun Luo

Copyright ( 2014 Peng Li et al. This is an open access article distributed under the Creative Commons Attribution License, which permits unrestricted use, distribution, and reproduction in any medium, provided the original work is properly cited.

\begin{abstract}
A new visible light response photocatalyst has been developed for $\mathrm{H}_{2}$ evolution from methanol solution by elemental doping. With lanthanum and cobalt dopants, the photoabsorption edge of $\mathrm{NaNbO}_{3}$ was effectively shifted to the visible light region. It is also found that the photoabsorption edge is effectively controlled by the dopant concentration. Under visible light irradiation, $\mathrm{H}_{2}$ was successfully generated over the doped $\mathrm{NaNbO}_{3}$ samples and a rate of $12 \mu \mathrm{mol} \cdot \mathrm{h}^{-1}$ was achieved over $(\mathrm{LaCo})_{0.03}(\mathrm{NaNb})_{0.97} \mathrm{O}_{3}$. Densityfunctional theory calculations show that Co-induced impurity states are formed in the band gap of $\mathrm{NaNbO}_{3}$ and this is considered to be the origin of visible-light absorption upon doping with La and Co.
\end{abstract}

\section{Introduction}

Because of the current energy crisis and environmental pollution from the consumption of fossil fuels, new source which can provide a big amount of maintainable energy must be developed in hurry. $\mathrm{H}_{2}$ is considered as a candidate of the next generation energy source because of its renewable, unlimited, and environmental friendly performances $[1,2]$. However, there are still several barriers to realize the practical utilization of $\mathrm{H}_{2}$ energy, and the produce of $\mathrm{H}_{2}$ is the most serious one. As the present $\mathrm{H}_{2}$ is mostly generated from the reformation of fossil fuel, a new method which can produce $\mathrm{H}_{2}$ with clean energy should be developed [3]. Photocatalysis has been developed as a candidate that can satisfy the demand of supplying $\mathrm{H}_{2}$ by splitting water with solar energy. In the past decades, a lot of photocatalysts were developed for producing $\mathrm{H}_{2}$ with high efficiency. But most of the photocatalysts, such as $\mathrm{TiO}_{2}, \mathrm{SrTiO}_{3}$, and $\mathrm{NaTaO}_{3}$, have only UV light responsibility, and the low visible light utilization limited the practical use of photocatalysis with solar light [4-6]. To improve the visible light absorption, the common method is doping with cations to adjust the electronic structures of photocatalysts [7]. When the cation dopants replace the positions of lattice cations or occupy the interstices in the crystal lattice, impurity energy levels might be generated within the band gap of the photocatalyst, which can extend the responsive region of photocatalytic reactions into visible light $[8,9]$.

$\mathrm{NaNbO}_{3}$ is a typical nontoxic and highly stable semiconductor which has abundant applications in photocatalysis. In many reports, $\mathrm{NaNbO}_{3}$ has been demonstrated to be a high efficiency photocatalyst for $\mathrm{H}_{2}$ generation [10-17]. Under the irradiation of UV light, $\mathrm{NaNbO}_{3}$ nanoparticles could reduce $\mathrm{H}_{2} \mathrm{O}$ to $\mathrm{H}_{2}$ with quite high efficiency with sacrificial agents [12]. Fiber-structured $\mathrm{NaNbO}_{3}$ was also verified to be useful in splitting pure $\mathrm{H}_{2} \mathrm{O}$ into $\mathrm{H}_{2}$ and $\mathrm{O}_{2}$ [10]. However, almost all the reported $\mathrm{NaNbO}_{3}$ photocatalysts are only sensitive to the UV light. Although iridium doped $\mathrm{NaNbO}_{3}$ was proved to be active in water splitting under visible light irradiation, 
the efficiency is still low and this method needs precious metal [18]. To achieve visible light photoactivity of $\mathrm{NaNbO}_{3}$ without previous metal dopant is still a big challenge. Cobalt, which is a typical transition element with partially occupied $d$ state, is commonly used as dopant to improve the visible light responsibility of wide band-gap photocatalysts [1922]. However, simply doping binary oxide with cobalt may increase the defect concentration and negatively affect the photocatalytic performance. Thus, codoping is more popular to balance the charge state and decrease the defects $[23,24]$. In this work, we developed a series of $\mathrm{NaNbO}_{3}$ doped with lanthanum and cobalt with $\mathrm{H}_{2}$ evolution activity under visible light irradiation. The further theoretical study indicates that the cobalt dopant creates new states in the band gap of $\mathrm{NaNbO}_{3}$ and provides the visible light absorption.

\section{Experimental Section}

2.1. Material Preparation. The samples were synthesized via a hydrothermal method [12]. In a typical synthesis of $\mathrm{NaNbO}_{3}$, $1.0 \mathrm{~g}$ of $\left(\mathrm{C}_{2} \mathrm{H}_{5} \mathrm{O}\right)_{5} \mathrm{Nb}$ and $0.24 \mathrm{~g}$ of $\mathrm{C}_{2} \mathrm{H}_{5} \mathrm{ONa}$ were added into $10 \mathrm{~mL}$ of 2-methoxyethanol and stirred at room temperature to form a clear colloid. Next, the mixture was stirred for 30 minutes and then heated to $120^{\circ} \mathrm{C}$ with a rate of $1^{\circ} \mathrm{C} \cdot \mathrm{min}^{-1}$ and maintained at this temperature until a dry gel was obtained. After that, $40 \mathrm{~mL}$ of $6 \mathrm{M} \mathrm{NaOH}$ solution was added to the powdered dry gel and stirred at room temperature to form a uniform precursor. Then, the mixture was transferred into a $50 \mathrm{~mL}$ Teflon sealed autoclave and heated at $180^{\circ} \mathrm{C}$ for $24 \mathrm{~h}$. Finally, the product was washed with distilled water until $\mathrm{pH}$ was lower than 8.0 and the obtained powder was dried at $70^{\circ} \mathrm{C}$ overnight. To synthesize $\mathrm{La}$, Co codoped $\mathrm{NaNbO}_{3}$, the dopant reagent $\mathrm{La}\left(\mathrm{CH}_{3} \mathrm{COO}\right)_{3}$, and $\mathrm{Co}\left(\mathrm{CH}_{3} \mathrm{COO}\right)_{2}$ were added in the first step and all the other procedures were the same.

2.2. Sample Characterization. The crystal structure of $\mathrm{NaNbO}_{3}$ powder was determined by an X-ray diffractometer (Rint2000, Rigaku Co., Japan) with $\mathrm{Cu}-\mathrm{Ka}$ radiation. The optical absorption spectra were measured with a UV-visible spectrophotometer (UV-2500PC, Shimadzu Co., Japan) using a $\mathrm{BaSO}_{4}$ reference. Scanning electron microscopy images were recorded with a field emission scanning electron microscopy (JSM-6701F, JEOL Co., Japan) operated at $15 \mathrm{kV}$.

2.3. Photocatalytic $\mathrm{H}_{2}$ Evolution. The $\mathrm{H}_{2}$ evolution experiments were carried out in a gas closed circulation system. In a typical experiment, 0.3 g catalyst was dispersed by a magnetic stirrer in a $\mathrm{CH}_{3} \mathrm{OH}$ solution $(220 \mathrm{~mL}$ distilled water and $50 \mathrm{~mL} \mathrm{CH}_{3} \mathrm{OH}$ ) in a Pyrex cell with a side window. Calculated amount of $\mathrm{H}_{2} \mathrm{PtCl}_{6}$ solution $(0.5 \mathrm{wt} \%)$ was added into the solution. The light source used for cocatalyst deposition was a $300 \mathrm{~W}$ Xe arc lamp without filter $(\lambda>300 \mathrm{~nm})$. After the $\mathrm{H}_{2}$ evolution rate became constant, the system was evacuated and an L-42 cutoff filter was added to the $300 \mathrm{~W}$ Xe arc lamp $(\lambda>420 \mathrm{~nm})$. The $\mathrm{H}_{2}$ evolution was measured by an in situ gas chromatograph (GC-8A, Shimadzu Co., Japan) with a thermal conductivity detector (TCD).
2.4. Theoretical Calculation. The band structures, densities of state (DOS), and partial densities of state (PDOS) of $\mathrm{NaNbO}_{3}$ and codoped $\mathrm{NaNbO}_{3}$ were calculated using the plane-wave density functional theory (DFT) with the CASTEP program package [25]. The doping concentration was set to $3.125 \%$ by, respectively, replacing a $\mathrm{Na}$ atom and a $\mathrm{Nb}$ atom by a $\mathrm{La}$ and a Co atom in a $2 \times 2 \times 1$ supercell. The electronic state of Co was $[\mathrm{Ar}] 3 d^{6}$ and high spin. The core electrons were replaced by ultrasoft pseudopotentials with a planewave basis cutoff energy of $410 \mathrm{eV}$, and the interactions of exchange and correlation were treated with Perdew-BurkeErnzerhof parameterization (PBE) of the generalized gradient approximation (GGA). The FFT grids of basis in all the models were $40 \times 40 \times 108$ and the $k$-point sets of $3 \times 3 \times 1$ were used.

\section{Results and Discussions}

The crystallographic structures of all the synthesized $\mathrm{NaNbO}_{3}$ samples were determined by X-ray diffraction (XRD) measurement (as shown in Figure 1(a)). All the observed diffraction peaks in the XRD patterns of $\mathrm{NaNbO}_{3}$ and doped $\mathrm{NaNbO}_{3}$ present good agreement with the reference data from the standard diffraction database (JCPDS073-0803), showing that every sample was well crystalized in a single phase with the space group of $\mathrm{Pbcm}$, which is the common phase of $\mathrm{NaNbO}_{3}$. However, slight shifts could be found when focusing on the particular diffraction peaks. Figure 1(b) gives the enlarged diffraction peaks with the highest intensity of $\mathrm{NaNbO}_{3}$ and doped $\mathrm{NaNbO}_{3}$. When doping $\mathrm{NaNbO}_{3}$ with $\mathrm{La}$ and $\mathrm{Co}$, the diffraction peak shifts to the smaller diffraction angle, suggesting that the unit cell of $\mathrm{NanbO}_{3}$ has a slight expansion. As the radius changes from $\mathrm{Na}^{+}(102 \mathrm{pm})$ and $\mathrm{Nb}^{5+}(64 \mathrm{pm})$ to $\mathrm{La}^{3+}(103.2 \mathrm{pm})$ and $\mathrm{Co}^{3+}(61 \mathrm{pm})$, such expansion of cell volume is understandable [26]. The XPS measurement (as shown in Figure S1 in Supplementary Material available online at http://dx.doi .org/10.1155/2014/380421) gives obvious evidence that the valance state of $\mathrm{Co}$ is +3 as no evident peak of $\mathrm{Co}^{2+}$ is observed [27]. The detailed lattice parameters of the asprepared doped and undoped $\mathrm{NaNbO}_{3}$ samples are shown in Table 1.

Since the morphology is an important factor which can greatly affect the photocatalytic performance, the scanning electron microscope (SEM) was further used to observe the morphology of the as-prepared samples and the SEM images of $\mathrm{NaNbO}_{3}$ and $(\mathrm{LaCo})_{0.05}(\mathrm{NaNb})_{0.95} \mathrm{O}_{3}$ are shown in Figure 2. The $\mathrm{NaNbO}_{3}$ sample is constituted by particles with the cubic morphology, and the cubic particles are generally $300 \sim 1000 \mathrm{~nm}$ in length. The obtained $\mathrm{NanbO}_{3}$ has the similar morphology as the sample synthesized by hydrothermal reaction in the previous report [12]. Although the crystal structure changes a little after doping with La and Co, the crystal growth process has almost no change. The doped sample has the same morphology as the pure $\mathrm{NaNbO}_{3}$.

UV-visible absorption spectra of $\mathrm{NaNbO}_{3}$ and $\mathrm{La}$, Co codoped $\mathrm{NaNbO}_{3}$ powder samples are shown in Figure 3(a). The pure $\mathrm{NabO}_{3}$ sample only has an intense absorption 
TABLE 1: Crystal structures of the as-prepared doped and undoped $\mathrm{NaNbO}_{3}$ samples.

\begin{tabular}{llcrc}
\hline Materials & Crystal system & \multicolumn{2}{c}{ Lattice parameters $(\AA)$} & \multicolumn{1}{c}{$c$} \\
& & $a$ & $5.5474(3)$ & $15.4988(6)$ \\
$\mathrm{NaNbO}_{3}(\mathrm{NaNb})_{0.99} \mathrm{O}_{3}$ & Orthorhombic & $5.5028(7)$ & $5.5542(2)$ & $15.5047(4)$ \\
$(\mathrm{LaCo})_{0.01}(\mathrm{LaCo})_{0.03}(\mathrm{NaNb})_{0.97} \mathrm{O}_{3}$ & Orthorhombic & $5.5098(4)$ & $5.5650(2)$ & $15.5321(3)$ \\
$(\mathrm{LaCo})_{0.05}(\mathrm{NaNb})_{0.95} \mathrm{O}_{3}$ & Orthorhombic & $5.5122(5)$ & $5.5674(4)$ & $15.5388(3)$ \\
\hline
\end{tabular}

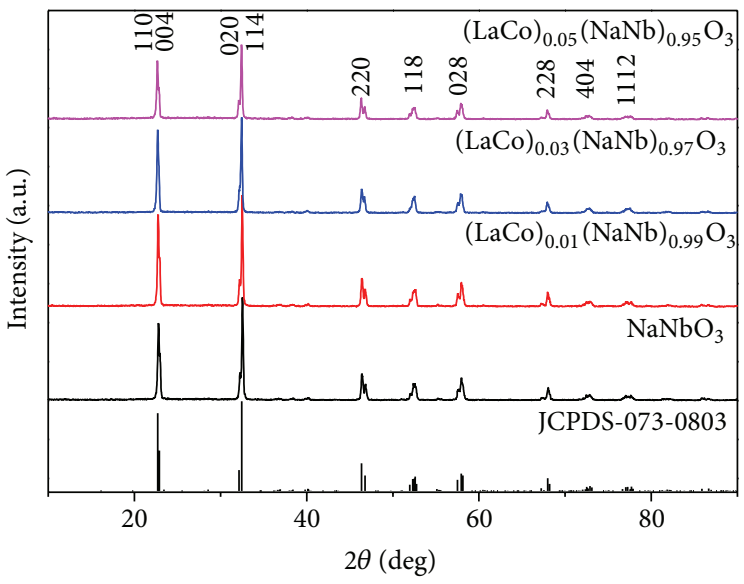

(a)

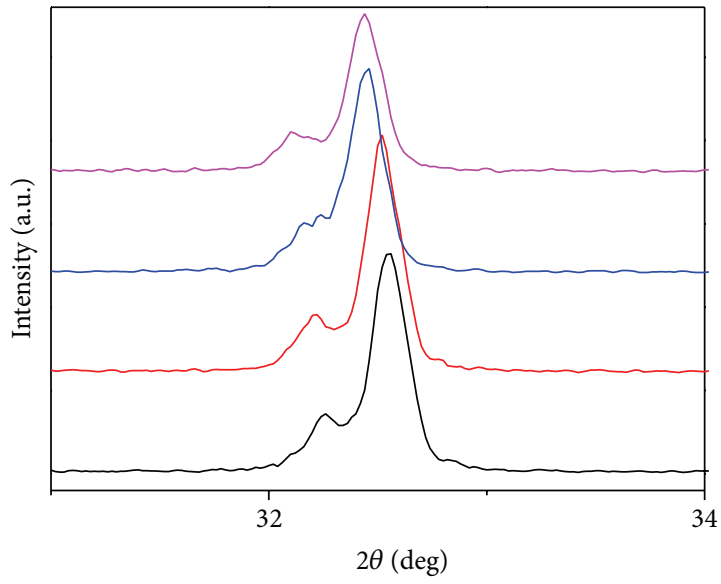

(b)

Figure 1: (a) XRD patterns of the as-prepared $\mathrm{NaNbO}_{3}$ and $\mathrm{La}$, Co codoped $\mathrm{NaNbO}_{3}$ compared with the standard $\mathrm{NaNbO}_{3} \mathrm{XRD}$ pattern. (b) The enlarged XRD patterns of the highest diffraction peak of $\mathrm{NaNbO}_{3}$.

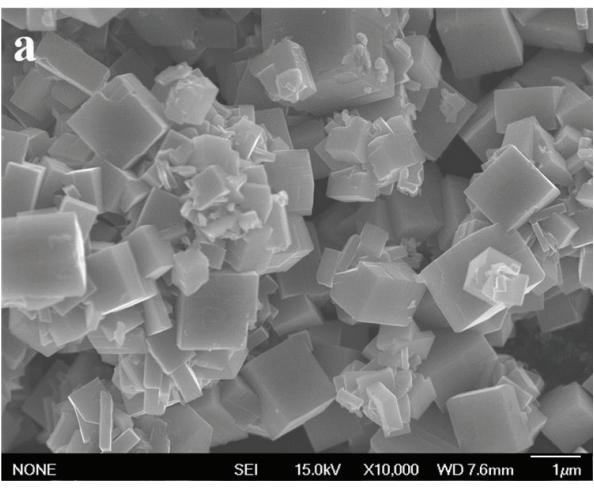

(a)

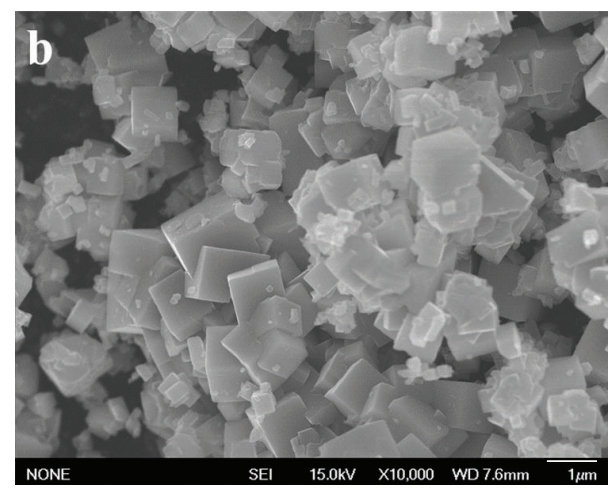

(b)

Figure 2: SEM images of the as-prepared (a) $\mathrm{NaNbO}_{3}$ and (b) La, Co codoped $\mathrm{NaNbO}_{3}$.

with steep edges in the UV region. Different from the pure $\mathrm{NaNbO}_{3}$, the samples have evident absorptions in the visible light region. The optical band gaps $E_{g}$ of the as-prepared $\mathrm{NaNbO}_{3}$ samples were determined according to the following equation:

$$
(\alpha h \nu)^{n}=A\left(h v-E_{g}\right),
$$

in which $\alpha, v, A$, and $E_{g}$ are absorption coefficient, light frequency, proportionality constant, and optical band gap, respectively [28]. The value of index $n$ depends on the property of materials, whereas $n=2$ for the direct transition and $n=1 / 2$ for the indirect transition. For $\mathrm{NaNbO}_{3}$, the index $n$ was determined to be $1 / 2$ according to the relationship between $\lg (\alpha h v)$ and $\lg \left(h v-E_{g}\right)$. For La, Co codoped $\mathrm{NaNbO}_{3}$, the indexes $n$ were determined to be 2. The different indexes of $\mathrm{NaNbO}_{3}$ and doped $\mathrm{NaNbO}_{3}$ indicate that $\mathrm{NaNbO}_{3}$ is an indirect band-gap semiconductor, while the doped $\mathrm{NaNbO}_{3}$ samples have direct transitions with visible light absorptions. From Figure 3(b), the values of the optical band gaps for $\mathrm{NaNbO}_{3},(\mathrm{LaCo})_{0.01}(\mathrm{NaNb})_{0.99} \mathrm{O}_{3}$, $(\mathrm{LaCo})_{0.03}(\mathrm{NaNb})_{0.97} \mathrm{O}_{3}$, and $(\mathrm{LaCo})_{0.05}(\mathrm{NaNb})_{0.95} \mathrm{O}_{3}$ are determined to be $3.42,2.74,2.70$, and $2.65 \mathrm{eV}$, respectively. 


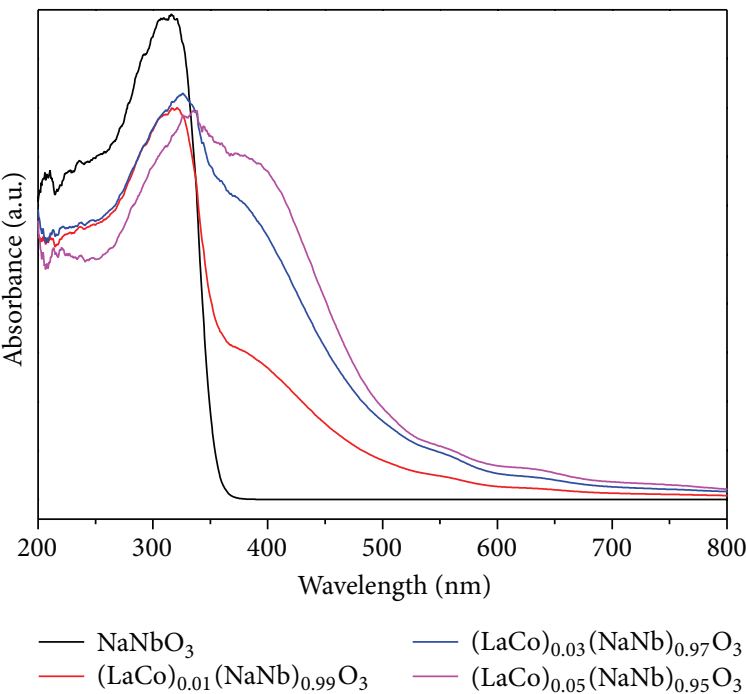

(a)

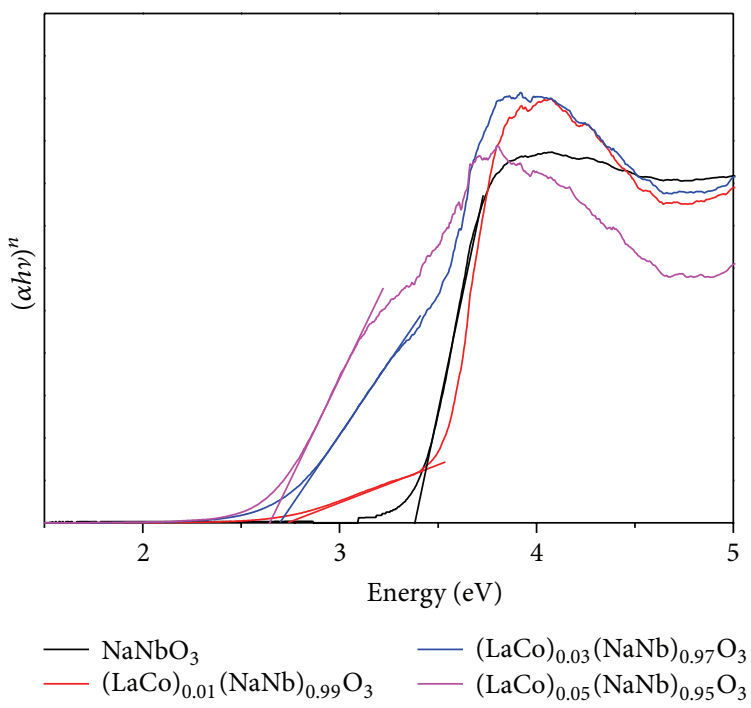

(b)

Figure 3: (a) UV-visible absorption spectra of the as-prepared $\mathrm{NaNbO}_{3}$ and $\mathrm{La}, \mathrm{Co}$ codoped $\mathrm{NaNbO}_{3}$. (b) The corresponding $(\alpha h \nu)^{n} \sim h \nu$ curves of the as-prepared $\mathrm{NaNbO}_{3}$ and $\mathrm{La}$, Co codoped $\mathrm{NaNbO}_{3}$.

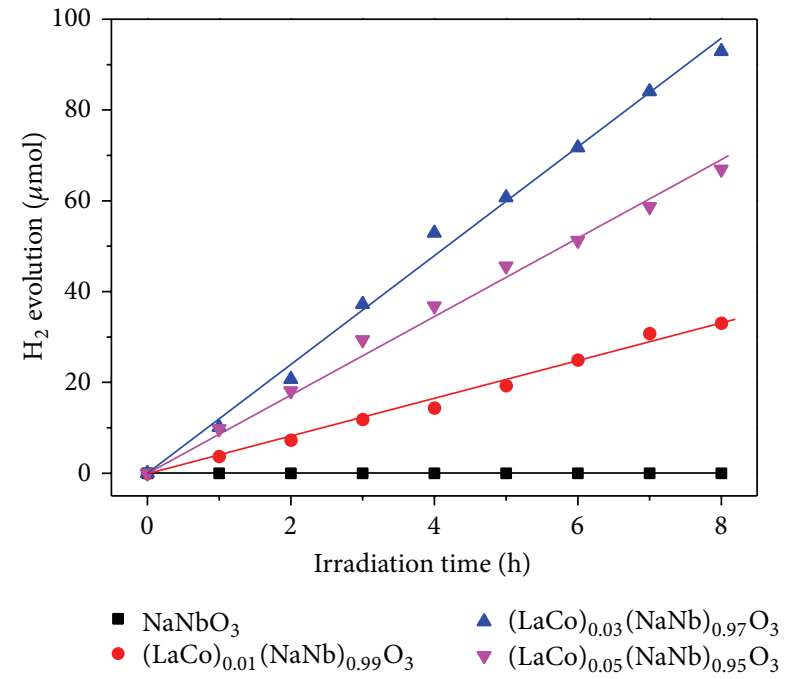

(a)

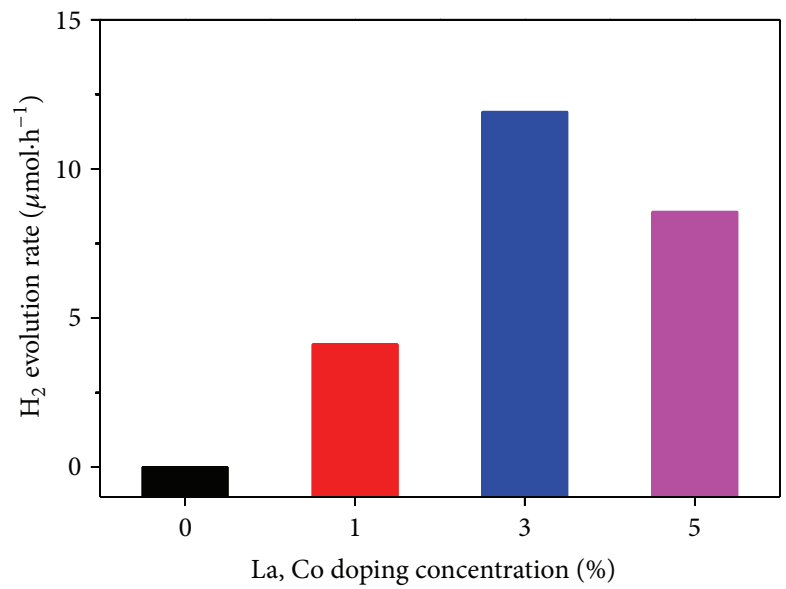

(b)

Figure 4: (a) Photocatalytic $\mathrm{H}_{2}$ evolutions from the aqueous methanol solution over the as-prepared $\mathrm{NaNbO}_{3}$ and $\mathrm{La}_{2} \mathrm{Co}_{\mathrm{codoped}} \mathrm{NaNbO}$ with $0.5 \mathrm{wt} \%$ Pt loading under the irradiation of visible light $(\lambda>420 \mathrm{~nm})$. (b) The comparison of average photocatalytic $\mathrm{H}_{2}$ evolution rates from the aqueous methanol solution over $\mathrm{NaNbO}_{3}$ and $\mathrm{La}$, Co codoped $\mathrm{NaNbO}_{3}$ with $0.5 \mathrm{wt} \%$ Pt loading under the irradiation of visible light $(\lambda>420 \mathrm{~nm})$.

With the increasing of doping concentration, the optical band gap of $\mathrm{NaNbO}_{3}$ is continuously decreasing.

The $\mathrm{H}_{2}$ evolutions from aqueous $\mathrm{CH}_{3} \mathrm{OH}$ solution $(50 \mathrm{~mL}$ $\mathrm{CH}_{3} \mathrm{OH}+220 \mathrm{~mL} \mathrm{H}_{2} \mathrm{O}$ ) over $\mathrm{NaNbO}_{3}$ and $\mathrm{La}$, Co codoped $\mathrm{NaNbO}_{3} \quad(0.3 \mathrm{~g})$ with $0.5 \mathrm{wt} \% \quad \mathrm{Pt}$ loading under the irradiation of visible light $(\lambda>420 \mathrm{~nm})$ are presented in Figure 4(a). As shown by the UV-visible absorption in the previous part, $\mathrm{NaNbO}_{3}$ has no visible light absorption. Under the irradiation of visible light, there is no $\mathrm{H}_{2}$ detected during the experiment in 8 hours, while the doped $\mathrm{NaNbO}_{3}$ samples exhibit photoactivities for $\mathrm{H}_{2}$ evolution in the presence of methanol as sacrificial reagent. $\mathrm{H}_{2}$ was generated almost linearly over all the doped samples in 8 hours. As plotted in Figure 4(b), the $\mathrm{H}_{2}$ evolution rates are significantly different: $(\mathrm{LaCo})_{0.03}(\mathrm{NaNb})_{0.97} \mathrm{O}_{3}>(\mathrm{LaCo})_{0.05}(\mathrm{NaNb})_{0.95} \mathrm{O}_{3}>$ $(\mathrm{LaCo})_{0.01}(\mathrm{NaNb})_{0.99} \mathrm{O}_{3}$. Over the best catalyst $(\mathrm{LaCo})_{0.03}(\mathrm{NaNb})_{0.97} \mathrm{O}_{3}, 11.9 \mu \mathrm{mol} \mathrm{H}_{2}$ could be produced every hour.

To understand the mechanism of visible light photocatalytic activity of $\mathrm{La}, \mathrm{Co}$ codoped $\mathrm{NaNbO}_{3}$, theoretical calculation based on density functional theory (DFT) was carried out. The density of states (DOS) in Figure 5 indicates that the undoped $\mathrm{NaNbO}_{3}$ has simple valence band maxima (VBM) and conduction band minima (CBM). Its VBM and CBM 


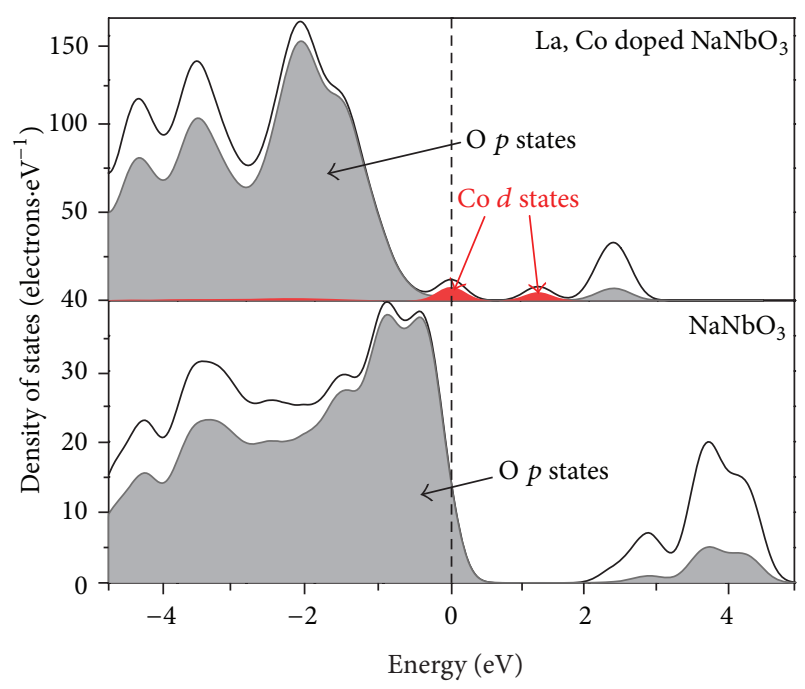

FIGURE 5: The calculated density of states and partial density of states of $\mathrm{NaNbO}_{3}$ and $\mathrm{La}$, Co codoped $\mathrm{NaNbO}_{3}$.

are mainly composited by $\mathrm{O} p$ states and $\mathrm{Nb} d$ states. Under light irradiation, the electrons are excited from $\mathrm{O} p$ orbitals to $\mathrm{Nb} d$ orbitals and the holes are left in $\mathrm{O} p$ orbitals. Then, the photogenerated electrons and holes migrate to the surface and react with water and sacrificial reagent, respectively. With La and Co doping, significant changes could be found with VBM and CBM. Two dopant states are observed between the original VBM and CBM, which narrow the band gap of doped $\mathrm{NaNbO}_{3}$ and induce the visible light absorption and visible light response $\mathrm{H}_{2}$ evolution activity. However, these two states are hybrid by Co $d$ states and $\mathrm{O} p$ states and Co $d$ states have larger combination ratio. Thus, the improved visible light absorption is mostly caused by the $d-d$ transition of Co. Since the electrons excited from $d$ states to $d$ states have a high backward transition rate, the photogenerated electrons could hardly migrate to the surface and perform photocatalytic reactions. This is the reason why the photoactivity of $\mathrm{La}$, Co codoped $\mathrm{NaNbO}_{3}$ under visible light is not as high as pure $\mathrm{NaNbO}_{3}$ under UV light. The general mechanism of the visible light activity over La, Co codoped $\mathrm{NaNbO}_{3}$ could be concluded in Figure 6. The doping with Co element creates new occupied and unoccupied energy levels in the band gap of $\mathrm{NaNbO}_{3}$. The transition between the new CBM and VBM could absorb visible and make the visible light photocatalytic reaction possible.

\section{Conclusions}

In conclusion, $\mathrm{La}$, Co codoped $\mathrm{NaNbO}_{3}$ were synthesized to realize the visible light response photocatalytic $\mathrm{H}_{2}$ evolution. The doped $\mathrm{NaNbO}_{3}$ samples showed narrower optical band gaps $\left(2.65,2.70\right.$, and $2.74 \mathrm{eV}$ for $(\mathrm{LaCo})_{0.05}(\mathrm{NaNb})_{0.95} \mathrm{O}_{3}$, $(\mathrm{LaCo})_{0.03}(\mathrm{NaNb})_{0.97} \mathrm{O}_{3}$, and $(\mathrm{LaCo})_{0.01}(\mathrm{NaNb})_{0.99} \mathrm{O}_{3}$, resp.) than the pure $\mathrm{NaNbO}_{3}(3.42 \mathrm{eV})$. In photocatalytic $\mathrm{H}_{2}$ evolution experiments, the doped $\mathrm{NaNbO}_{3}$ samples showed activity under the visible light irradiation, while the undoped

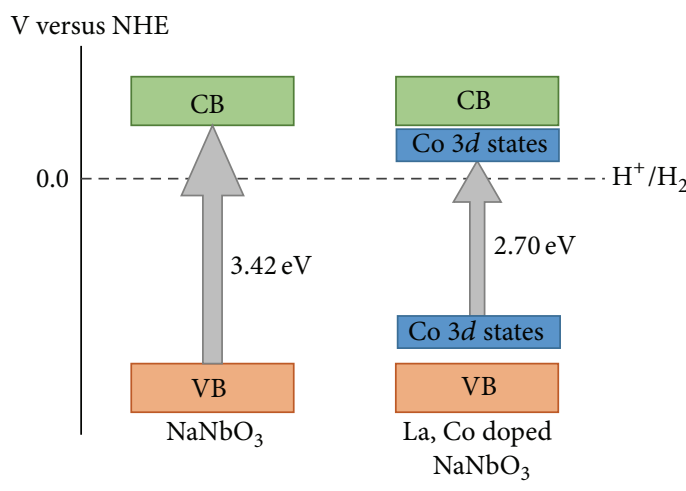

Figure 6: The schematic band structures of $\mathrm{NaNbO}_{3}$ and $\mathrm{La}$, Co codoped $\mathrm{NaNbO}_{3}$.

$\mathrm{NaNbO}_{3}$ was not active. According to the theoretical calculation, the visible light activity of $\mathrm{La}$, Co codoped $\mathrm{NaNbO}_{3}$ could be attributed to the new impurity electronic states of Co dopant. Therefore, this work presented a new material for visible light photocatalytic $\mathrm{H}_{2}$ evolution.

\section{Conflict of Interests}

The authors declare that there is no conflict of interests regarding the publication of this paper.

\section{Acknowledgments}

The authors thank Professor Naoto Umezawa for the result discussion and Dr. Akihiro Tanaka and Dr. Hideo Iwai of Materials Analysis Station of NIMS for the XPS measurement and analysis. This work was supported by Japan Science and Technology Agency (JST) and Precursory Research for Embryonic Science and Technology (PRESTO) program.

\section{References}

[1] A. J. Bard and M. A. Fox, "Artificial photosynthesis: solar splitting of water to hydrogen and oxygen," Accounts of Chemical Research, vol. 28, no. 3, pp. 141-145, 1995.

[2] T. J. Meyer, "Chemical approaches to artificial photosynthesis," Accounts of Chemical Research, vol. 22, pp. 163-170, 1989.

[3] M. D. Hernández-Alonso, F. Fresno, S. Suárez, and J. M. Coronado, "Development of alternative photocatalysts to $\mathrm{TiO}_{2}$ : challenges and opportunities," Energy and Environmental Science, vol. 2, no. 12, pp. 1231-1257, 2009.

[4] Y. Yoshida, M. Matsuoka, S. C. Moon, H. Mametsuka, E. Suzuki, and M. Anpo, "Photocatalytic decomposition of liquid-water on the Pt-loaded $\mathrm{TiO}_{2}$ catalysts: effects of the oxidation states of Ptspecies on the photocatalytic reactivity and the rate of the back reaction," Research on Chemical Intermediates, vol. 26, no. 6, pp. 567-574, 2000.

[5] H. Kato and A. Kudo, "New tantalate photocatalysts for water decomposition into $\mathrm{H}_{2}$ and $\mathrm{O}_{2}$," Chemical Physics Letters, vol. 295, no. 5-6, pp. 487-492, 1998. 
[6] K. Domen, S. Naito, M. Soma, T. Onishi, and K. Tamaru, "Photocatalytic decomposition of water vapour on an $\mathrm{NiO}-\mathrm{SrTiO}_{3}$ catalyst," Journal of the Chemical Society, Chemical Communications, no. 12, pp. 543-544, 1980.

[7] H. Tong, S. Ouyang, Y. Bi, N. Umezawa, M. Oshikiri, and J. Ye, "Nano-photocatalytic materials: possibilities and challenges," Advanced Materials, vol. 24, no. 2, pp. 229-251, 2012.

[8] J. Y. Cao, Y. J. Zhang, H. Tong, P. Li, T. Kako, and J. H. Ye, "Selective local nitrogen doping in $\mathrm{TiO}_{2}$ electrode for enhancing photoelectrochemical water splitting," Chemical Communications, vol. 48, pp. 8649-8651, 2012.

[9] J. W. Shi, J. H. Ye, L. J. Ma, S. X. Ouyang, D. W. Jing, and L. J. Guo, "Site-selected doping of upconversion luminescent $\mathrm{Er}^{3+}$ into $\mathrm{SrTiO}_{3}$ for visible-light-driven photocatalytic $\mathrm{H}_{2}$ or $\mathrm{O}_{2}$ evolution," Chemistry, vol. 18, no. 24, pp. 7543-7551, 2012.

[10] H. F. Shi, X. K. Li, D. F. Wang, Y. P. Yuan, Z. G. Zou, and J. H. $\mathrm{Ye}$, "NaNbO${ }_{3}$ nanostructures: facile synthesis, characterization, and their photocatalytic properties," Catalysis Letters, vol. 132, pp. 205-212, 2009.

[11] P. Li, S. Ouyang, G. Xi, T. Kako, and J. Ye, “The effects of crystal structure and electronic structure on photocatalytic $\mathrm{H}_{2}$ evolution and $\mathrm{CO}_{2}$ reduction over two phases of perovskitestructured $\mathrm{NaNbO}_{3}$," The Journal of Physical Chemistry C, vol. 116, no. 14, pp. 7621-7628, 2012.

[12] G. Li, T. Kako, D. Wang, Z. Zou, and J. Ye, "Synthesis and enhanced photocatalytic activity of $\mathrm{NaNbO} 3$ prepared by hydrothermal and polymerized complex methods," Journal of Physics and Chemistry of Solids, vol. 69, no. 10, pp. 2487-2491, 2008.

[13] P. Li, H. Xu, L. Liu et al., "Constructing cubic-orthorhombic surface-phase junctions of $\mathrm{NaNbO}_{3}$ towards significant enhancement of $\mathrm{CO}_{2}$ photoreduction," Journal of Materials Chemistry A, vol. 2, no. 16, pp. 5606-5609, 2014.

[14] N. Chen, G. Li, and W. Zhang, "Effect of synthesis atmosphere on photocatalytic hydrogen production of $\mathrm{NaNbO}_{3}$," Physica $B$, vol. 447, pp. 12-14, 2014.

[15] G. Li, W. Wang, N. Yang, and W. F. Zhang, "Composition dependence of $\mathrm{AgSbO}_{3} / \mathrm{NaNbO}_{3}$ composite on surface photovoltaic and visible-light photocatalytic properties," Applied Physics A: Materials Science \& Processing, vol. 103, pp. 251-256, 2011.

[16] G. Li, Z. Yi, Y. Bai, W. Zhang, and H. Zhang, "Anisotropy in photocatalytic oxidization activity of $\mathrm{NaNbO}_{3}$ photocatalyst," Dalton Transactions, vol. 41, no. 34, pp. 10194-10198, 2012.

[17] X. Li, G. Li, S. Wu, X. Chen, and W. Zhang, "Preparation and photocatalytic properties of platelike $\mathrm{NaNbO}_{3}$ based photocatalysts," Journal of Physics and Chemistry of Solids, vol. 75, pp. 491-494, 2014.

[18] A. Iwase, K. Saito, and A. Kudo, "Sensitization of $\mathrm{NaMO}_{3}$ (M: $\mathrm{Nb}$ and $\mathrm{Ta}$ ) photocatalysts with wide band gaps to visible light by Ir doping," Bulletin of the Chemical Society of Japan, vol. 82, pp. 514-518, 2009.

[19] J. Choi, H. Park, and M. R. Hoffmann, "Effects of single metalion doping on the visible-light photoreactivity of $\mathrm{TiO}_{2}$," The Journal of Physical Chemistry C, vol. 114, no. 2, pp. 783-792, 2010.

[20] D. Dvoranova, V. Brezova, M. Mazur, and M. A. Malati, "Investigations of metal-doped titanium dioxide photocatalysts," Applied Catalysis B, vol. 37, no. 2, pp. 91-105, 2002.

[21] M. Iwasaki, M. Hara, H. Kawada, H. Tada, and S. Ito, "Cobalt ion-doped $\mathrm{TiO}_{2}$ photocatalyst response to visible light," Journal of Colloid and Interface Scienc, vol. 224, pp. 202-204, 2000.
[22] B. Zhou, X. Zhao, H. Liu, J. Qu, and C. P. Huang, "Visiblelight sensitive cobalt-doped $\mathrm{BiVO}_{4}\left(\mathrm{Co}-\mathrm{BiVO}_{4}\right)$ photocatalytic composites for the degradation of methylene blue dye in dilute aqueous solutions," Applied Catalysis B, vol. 99, pp. 214-221, 2010.

[23] Z. G. Yi and J. H. Ye, "Band gap tuning of $\mathrm{Na}_{1-x} \mathrm{La}_{x} \mathrm{Ta}_{1-x} \mathrm{Co}_{x} \mathrm{O}_{3}$ solid solutions for visible light photocatalysis," Applied Physics Letters, vol. 91, Article ID 254108, 2007.

[24] Z. G. Yi and J. H. Ye, "Band gap tuning of $\mathrm{Na}_{1-x} \mathrm{La}_{x} \mathrm{Ta}_{1-x} \mathrm{Cr}_{x} \mathrm{O}_{3}$ for $\mathrm{H}_{2}$ generation from water under visible light irradiation," Journal of Applied Physics, vol. 106, Article ID 074910, 2009.

[25] M. D. Segall, P. J. D. Lindan, M. J. Probert et al., "First-principles simulation: ideas, illustrations and the CASTEP code," Journal of Physics Condensed Matter, vol. 14, no. 11, pp. 2717-2744, 2002.

[26] R. Shannon, "Revised effective ionic radii and systematic studies of interatomic distances in halides and chalcogenides," Acta Crystallographica A, vol. 32, pp. 751-767, 1976.

[27] M. C. Biesinger, B. P. Payne, A. P. Grosvenor, L. W. M. Lau, A. R. Gerson, and R. S. C. Smart, "Resolving surface chemical states in XPS analysis of first row transition metals, oxides and hydroxides: Cr, Mn, Fe, Co and Ni," Applied Surface Science, vol. 257, no. 7, pp. 2717-2730, 2011.

[28] M. A. Butler, "Photoelectrolysis and physical properties of the semiconducting electrode $\mathrm{WO}_{2}$," Journal of Applied Physics, vol. 48, pp. 1914-1920, 1977. 

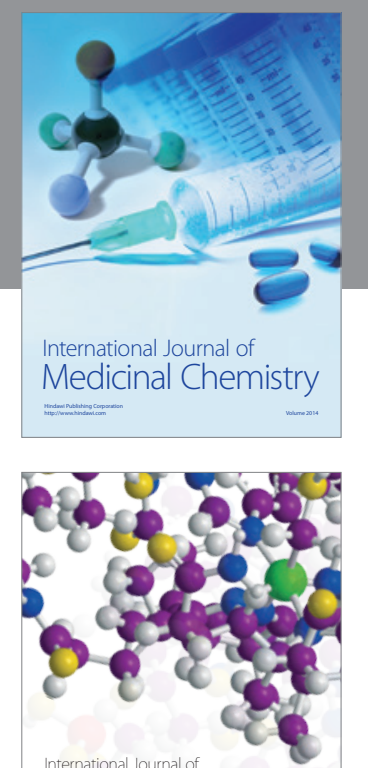

\section{Carbohydrate} Chemistry

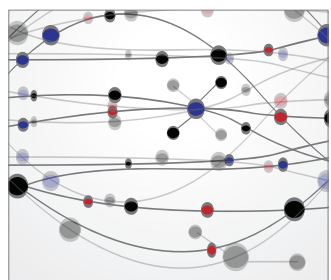

The Scientific World Journal
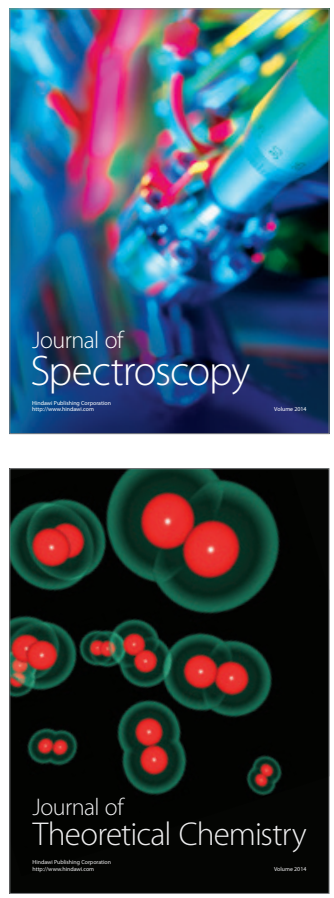
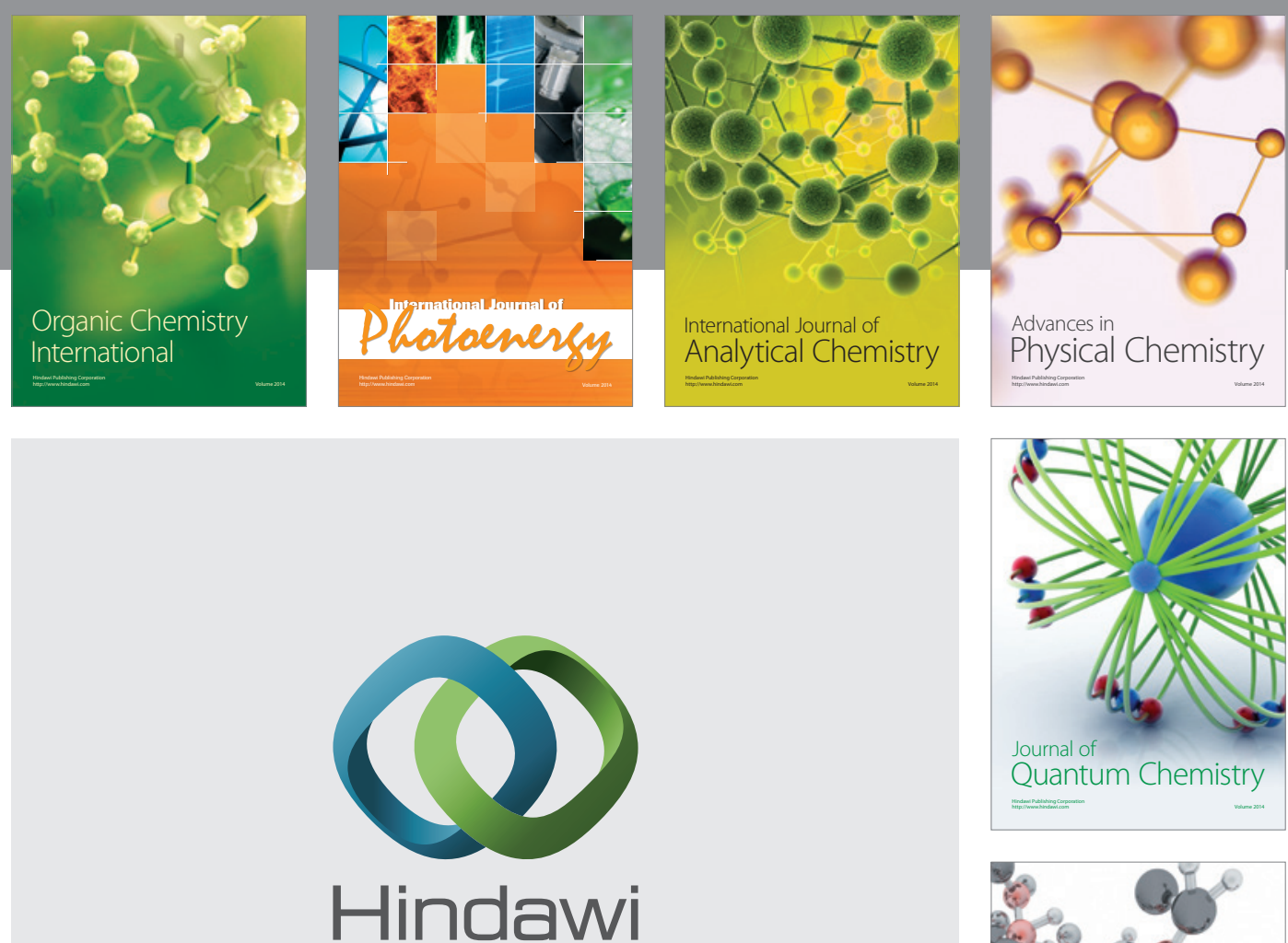

Submit your manuscripts at

http://www.hindawi.com

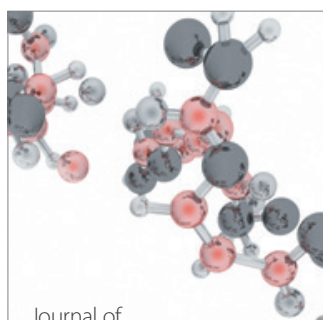

Analytical Methods

in Chemistry

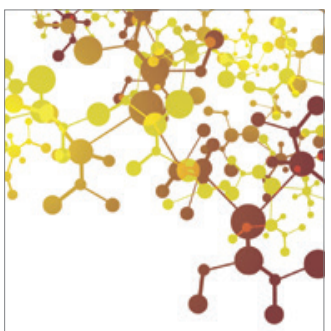

Journal of

Applied Chemistry

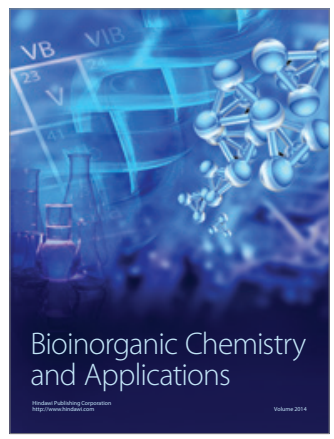

Inorganic Chemistry
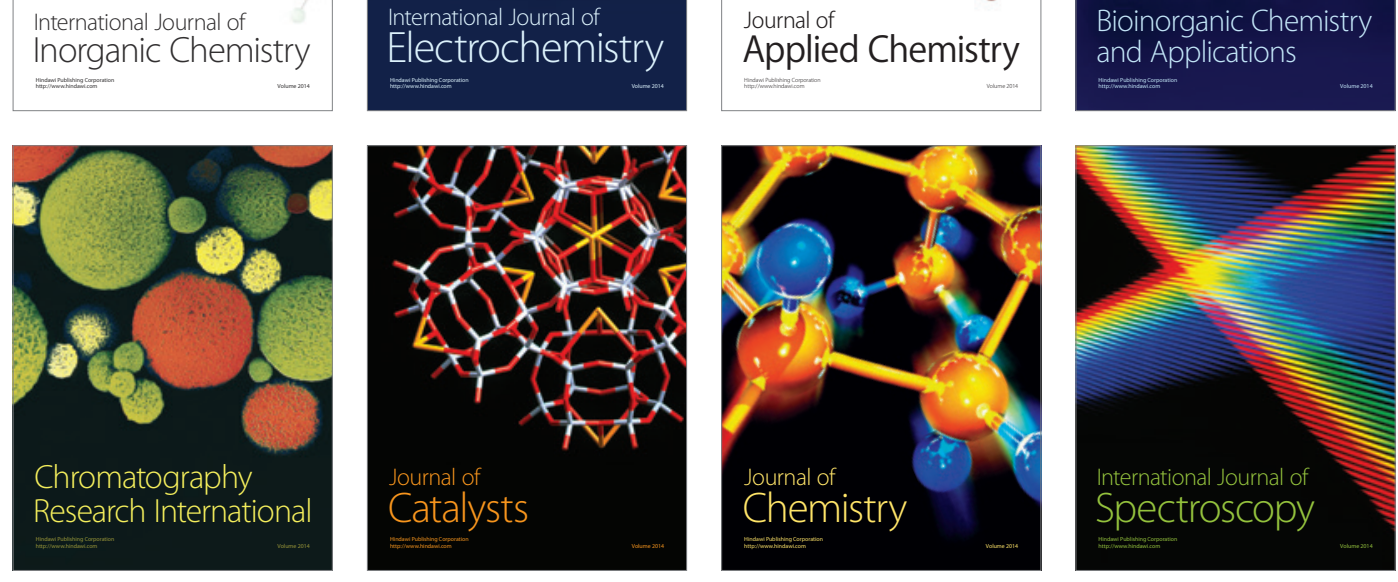